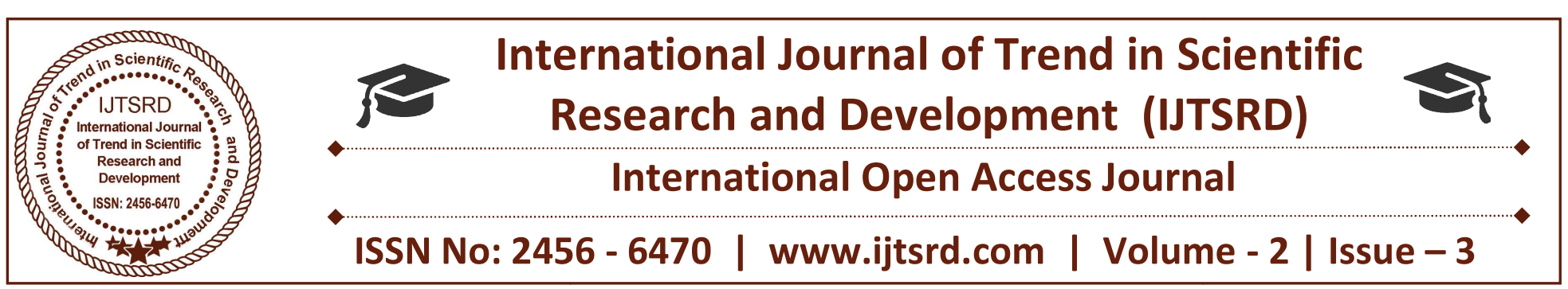

\title{
Android Application for College Management System
}

\author{
Aarti Erande, Vaibhavi Avachat, Sumit Ghardale, Prof. Bhavesh Shah \\ Suman Ramesh Tulsiani Technical Campus, Pune, Maharashtra, India
}

\begin{abstract}
In a world state of affairs, like faculty field, the information is inside the kind of notice, hand-written manual, verbal message, is being unfold among the students. Currently it's of the essence to not entirely use the predictable varieties of statement, but together new forms like phone technology, for faster and easier communication among the students. The core set up of this project is to implement automaton based collage Management application for advancement of multinational and educational system. Throughout this paper we have a tendency to tend to develop degree application that provided information like assignments, result and attending, notices and conjointly the department details. Here we have a tendency to tend to together use Authentication, simply the once passwords (OTP) play a major role for authentication and accustomed provide higher layer of security over static passwords. Students attending are to boot monitored by the applying. We have a tendency to tend to together propose the notification that send notification of recent activity to the students, employees or box whether or not or not they unit of measurement on-line or offline.
\end{abstract}

Keywords: Forum, Attendance System, Shared Data, Access Data using Attribute, OTP Login, Share Post

\section{INTRODUCTION}

Today, mobile devices became a vital a neighborhood of human life. Users access their emails, social networks, bank accounts, and varied various websites via mobile devices. but still some areas that do not appear to be upgrade with mobile

devices. ancient approach used in school where faculty use board to share any information and teacher dictates the notes earlier than students and students collectively write notes in their notebook. This technique is time overwhelming for teacher and students. simply just in case any pressing notices by higher management like box or principal take time to attain everyone. currently it's of the required to not entirely use the sure styles of statement, but collectively new forms like phonephone technology, for faster and easier communication among the students. The approach of communication is automaton. throughout this paper we tend to tend to develop AN application that provided information like assignments, timetables of examinations, result and act, notices and so the department details. Here we tend to tend to collectively use Authentication, just one occasion passwords (OTP) play a major role for authentication and used to provide higher layer of security over static passwords. Student's act is in addition monitored by the applying. we tend to tend to collectively propose the notification that send notification of recent activity to the students, staff or box whether or not or not they area unit on-line or offline. In [1] is being developed for AN engineering school to stay up and facilitate fast access to information. For this the users ought to be registered with the system once that they will access still as modify info as per the permissions given to them. In [2] assists in automating the current manual system. Typically this can be\} often a paperless work. it's going to be monitored and controlled remotely. It reduces the person power required. [4] discusses the manoeuvre of the management information in instruction. On the concept of a comprehensive 
investigation and analysis on the scholar management in instruction, we tend to tend to determine the models of the college students' management information by adopting the advanced information technology, and construct the scholar management information platform. Moreover, we tend to tend to investigate the characteristics of the information management in instruction, and elaborate the methods to unravel the difficulties confronting at intervals the scholars management of the higher education. Finally, the key methodology and technology to carry out the information management platform area unit given.

\section{RELATED WORK}

Paper1: Research Paper on College Management System

In this Paper is being developed for academic degree engineering school to stay up and facilitate fast access to information. For this the users ought to be registered with the system once that they will access more as modify info as per the permissions given to them. CMS is academic degree electronic network based application that aims at providing information to any or all the degree of management with in an exceedingly company. this technique is usually used as a knowledge/information management system for the varsity. For a given student/staff (technical/Nontechnical) can access the system to either transfer or transfer some information from the data.

\section{Paper2: Web Based Student Information Management System}

In this Paper assists in automating the current manual system. this will be a paperless work. it's monitored and controlled remotely. It reduces the person power required. It provides correct information invariably. Malpractice is reduced. All years on gathered information is saved and should be accessed at any time. the data that's keep at intervals the repository helps in taking intelligent decisions by the management. so it's higher to possess an online based information Management system. All the stakeholders, college and management can get the required information directly. this technique is crucial at intervals the colleges/hostels and universities.

\section{Paper3: Android College Campus}

In this Paper The golem based Mobile field is developed to produce students with information regarding library due dates, any placement activities, general notices, attending and marks details. This information have to be compelled to be provided to students in associate degree extremely worth effective means that. so to appreciate identical, we have got developed this application, whereby students can access this information victimization their golem enabled mobiles. The mode of communication is golem. Students needn't line up near board / log on to varsity electronic computer for any of the upper than mentioned details. merely acquire the proximity limit of one of the many out there golem points and explore the service

Paper4: The development and design of the student management system based on the network environment.

In this paper discusses the maneuver of the management knowledge in instruction. On the thought $L$ of a | comprehensive investigation and analysis on the scholar management in instruction, we've a bent to tend to determine the models of the varsity students' management knowledge by adopting the advanced knowledge technology, and construct the scholar management knowledge platform. Moreover, we've a bent to tend to research the characteristics of the knowledge management in instruction, and elaborate the ways that to unravel the difficulties endeavor at intervals the students management of the upper education. Finally, the key methodology and technology to hold out the knowledge management platform unit given

\section{Paper5: Mobile Web Based Android Application for College Management System}

The system offers responsibility, time savings and simple management. Students and their parents additionally can browse results, human activity and data details practice this application. to boot students can browse details, notifications anywhere and anytime. the applying will greatly amendment and speed up the result preparation and management technique. It provides high security and a system that reduces the work and resources required in ancient technique. The projected system provides the new means that of computing and displaying associate degree operations with responsive and engaging 
user-interface. Thus, on the thought of literature survey and by analyzing the prevailing system, we have got return to a conclusion that the propose system will not alone aid the automation to the college, but additionally can facilitate to digitalize the system and in turn facilitate to deploy resources efficiently.

\section{EXISTING SYSTEM}

Traditional approach utilised in school where college use bulletin board to share any information. And teacher dictates the notes before of students and students to boot write notes in their notebook. This methodology is time intense for teacher and students. simply just in case any imperative notices by higher management like box or Principal take time to attain everyone. some time few students out of college premises so as that they don't get that imperative notices. this can be creating some draw back thereto Student.

\section{Existing System Disadvantages:}

1.Existing System is not efficient because sometimes it is time consuming.

2.Existing system fails in case of any emergency to HOD and principal.

3.Staff communicates with HOD by meeting face to face.

\section{OBJECTIVE}

1.Providing the online interface for students, faculty etc.
2.Increasing the efficiency of college record management.

3. Decrease time required to access and deliver student records.

4. To make the system more secure.

5. Decrease time spent on non-value added tasks

\section{PROPOSED SYSTEM}

We planned AN automaton App for collage activities. This innovative system permits school faculty to share important info to boot as notifications with students through our App. It consists of OTP primarily based Teacher, box and Principal login in conjunction with student login. Since school teacher operates through Mobile App and document uploading is a smaller amount sophisticated through a mobile, the teacher login is to be performed through a mobile App. teacher may transfer documents of subject info, notifications, e notes and update attendances etc through their provided login. The documents area unit uploaded by teacher to altogether totally different corresponding Departments. Here students only scan event and transfer info of their specific semester. Teacher may access and upload/edit documents to any semester or add any Post as desired. Teacher to boot updates student event by exploitation automaton Application. box to boot login through its mobile device, his role is to observance specific division activities and share document, notes like timetable document. and additionally the role of principal is to look at overall activities perform by altogether totally different departments.

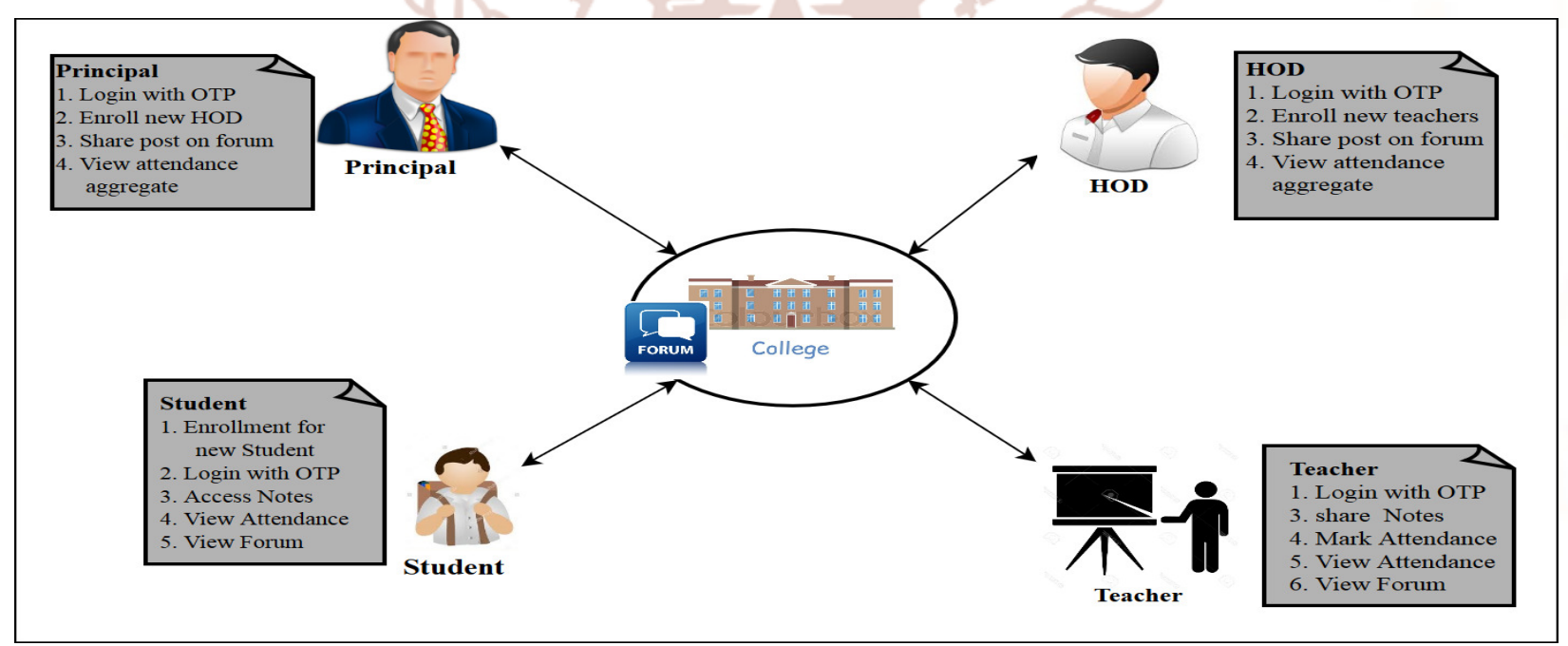




\section{Proposed System Advantages:}

1. OTP based Login that permits registered user to login an preventing unauthorized access.

2. The android mobile user will be able make quick download from anywhere using internet.

3. Usage of application can greatly cut back time in document sharing.

\section{ALGORITHMS}

\section{Algorithm 1: K-means Algorithm}

Let $\mathrm{X}=\left\{\mathrm{x}_{1}, \mathrm{x}_{2}, \mathrm{x}_{3}, \ldots \ldots, \mathrm{x}_{\mathrm{n}}\right\}$ be the set of data points and $\mathrm{V}=\left\{\mathrm{v}_{1}, \mathrm{v}_{2}, \ldots \ldots, \mathrm{v}_{\mathrm{c}}\right\}$ be the set of centers.

1) Randomly select ' $c$ ' cluster centers.

2) Calculate the distance between each data point and cluster centers.

3) Assign the data point to the cluster center whose distance from the cluster center is minimum of all the cluster centers..

4) Recalculate the new cluster center using:

$$
v_{i}=\left(1 / c_{i}\right) \sum_{j=1}^{c_{i}} x_{i}
$$

where, ' $c{ }_{i}$ ' represents the number of data points in $i^{\text {th }}$ cluster.

5) Recalculate the distance between each data point and new obtained cluster centers.

6) If no data point was reassigned then stop, otherwise repeat from step 3).
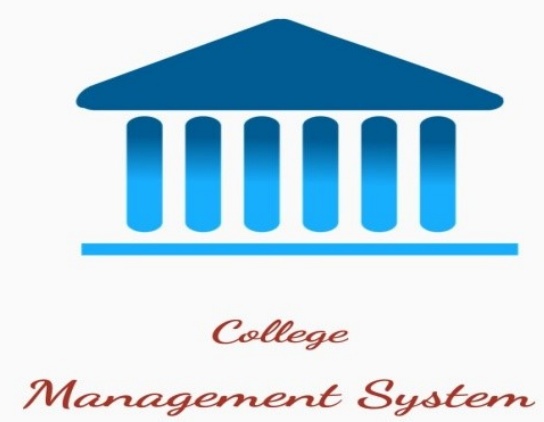

\section{My College Campus}

HOME

GET CONNECTED

Welcome

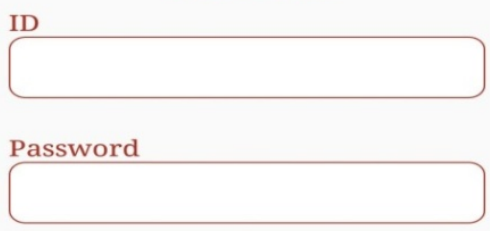

SIGN IN

SIGN UP

\section{Algorithm 2: Authentication Process}

1. During authorization, besides a user's login and password, a user will be asked for a one-time password that he/she will have to enter in the form after generating it with one of our tokens.

2. The one-time password is sent through the API to Protectimus.

3. In real-time mode, the OTP and the user are verified, and your application instantly receives a positive or a negative response.

4. Your application responds to the authentication attempt based on the response received.

\section{RESULT}

\section{Student Home}

Hello mauli
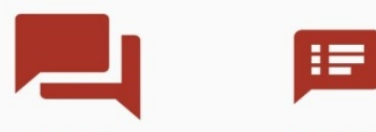

Forum

Notices
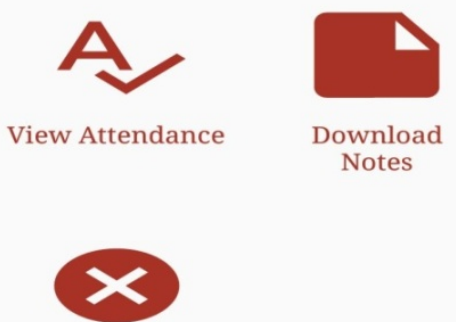

Logout 

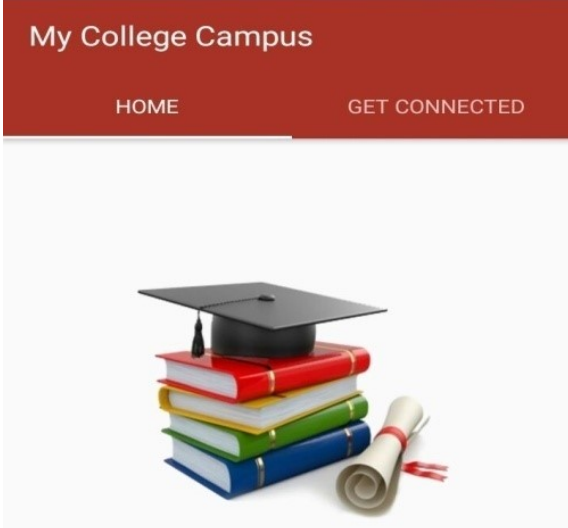

Welcome to College Campus App

\section{REFERENCES}

1. Lalit Mohan Joshi, "A Research Paper on College Management System", International Journal of Computer Applications (0975-8887) Volume 122 - No.11, July 2015.

2. ShiplaHamale, ThakurGaneshsingh,SyedArshadH ussain "Android College Campus ",International journal of ethics in Engineering \& Management Education,ISSN:2348-4748, 2014

3. S.R. Bharamagoudar, Geeta R.B., S.G.Totad (2013 "Web Based Student Information Management System",International Journal of Advanced Research in Computer and Communication Engineering Vol. 2, Issue 6, June 2013.

4. Zhi-gang YUE, You-wei JIN, "The development and design of the student management system based on the network environment" 2010

\section{CONCLUSION AND FUTURE SCOPE}

We proposed system on on-line server that enables teacher to transfer notes and updates Attendances and students could read own group action, transfer needed documents through their automaton device. owning to this faculty activities and spot share with student directly. we offer OTP based mostly authentication to forestall unauthorized access.

In future we introduce, Parent Teacher Communication may additionally be developed. Attendance proportion calculators are often introduced. Assignments are often submitted through on-line and mail etc.Online library system is often introduced.

\section{ACKNOWLEDGEMENTS}

This work is supported by Prof. Bhavesh Shah (Suman Ramesh Tulsiani Technical Campus Faculty of Engineering)
5. A.J.Kadam, Aradhana Singh, Komal Jagtap, Srujana Tankala,"Mobile Web Based Android Application for College Management Sysytem"2017

6. Priyanka Jichkar1,Kalyani Gawande2, Arshadkhan Pathan3, Prof. Gangotri Nathaney, "Android Based Department App - Using Smart Phone" 2017

7. Vishwakarma R Ganesh,"Android College Management System",2016 